\title{
Health beliefs around stroke in an urban South African setting - a qualitative study
}

Shane Murphy ( $\square$ murphy.shanedarren@gmail.com )

University of Witwatersrand https://orcid.org/0000-0001-5387-6661

Shabir Moosa

University of Witwatersrand https://orcid.org/0000-0001-7849-9751

\section{Research Article}

Keywords: Health belief model, primary care, healthcare service, stroke, health behaviour, access to care

Posted Date: January 18th, 2022

DOI: https://doi.org/10.21203/rs.3.rs-1266323/v1

License: (c) (i) This work is licensed under a Creative Commons Attribution 4.0 International License. Read Full License 


\section{Health beliefs around stroke in an urban South African setting: a qualitative study}

Authors: Shane Murphy ${ }^{1}$, Shabir Moosa ${ }^{1}$

\section{Affiliations}

${ }^{I}$ Department of Family Medicine and Primary Care, Faculty of Health Sciences, University of the Witwatersrand, Parktown, Johannesburg, South Africa

Corresponding author:

Shane Murphy

Murphy.shanedarren@gmail.com 
Abstract

Individuals in developing countries are disproportionately affected by stroke disease, where healthcare services are overwhelmed, and inadequate health literacy stifles preventive and promotive health behaviours. This research aimed to explore the experiences and views of patients with stroke in an urban South African setting. Semi-structured interviews were conducted with 15 patients living with stroke disease, recruited from an outpatient department in an urban setting. Participants in this study frequently described stroke disease as a fate worse than death. They frequently cited cultural, spiritual and psychological factors as causes for their stroke. Participants were unaware of any potential therapies and viewed the healthcare system as unhelpful and frustrating. These findings highlight the lived-experiences of patients with debilitating stroke disease in a health system that is hospi-centric with a curative design. Poor health literacy disables appropriate health-related preventive and promotive behaviours around stroke disease that disproportionately affects the marginalised of society.

\section{Keywords}

Health belief model; primary care; healthcare service; stroke; health behaviour; access to care 


\section{Health beliefs around stroke in an urban South African setting: a qualitative study}

\section{Introduction}

Stroke is the leading cause of morbidity, and the second leading cause of mortality in the world - responsible for 9.5\% of all deaths globally (Feigin \& Krishnamurthi, 2011; Lozano et al., 2012). Nearly $85 \%$ of this burden occurs in developing nations (Bham \& Ross, 2005), compounded by the fact that developing countries have markedly reduced capability to support victims of stroke (Feris \& Naicker, 2020). Research from South Africa shows that the local burden of stroke disease mirrors international data (Maredza et al., 2016). This burden is predicted to steadily increase over the coming years as South Africa's protracted epidemiologic transition sees a burgeoning mix of communicable and non-communicable diseases that heighten the risk of stroke disease (Bradshaw et al., 2019). This high burden of stroke disease reflects the extant under-performance and underutilization of primary health care service in South Africa (Mayosi \& Benatar, 2014), given that nearly 80\% of strokes can be prevented through the reduction of modifiable risk factors for stroke (Goldstein et al., 2006). It is arguable that the failure to reduce the burden of stroke disease by the South African healthcare system is due to an ingrained centralized model of care that is skewed towards therapeutic services instead of preventive and holistic health services.

The post-apartheid South African government has invested heavily in primary health care to increase efficacy, acceptability and accessibility of care to South African citizens (Day \& Zondi, 2019). Despite the sustained bolstering of PHC services to facilitate comprehensive and integrative care that prioritises health promotion and prevention, the incidence and burden of stroke disease has steadily increased and is predicted to continue in this fashion. This increase is contradictory to the literature on improved care of several non-communicable (NCD's) and communicable diseases (CD's) as modifiable risk factors for stroke (Bradshaw et al., 2019; Day \& Zondi, 2019). Notable modifiable risk factors in the South African setting include hypertension, diabetes, obesity, dyslipidaemia, HIV and other infectious diseases, tobacco smoking and harmful alcohol use. A summary of these, alongside their established effect sizes (in international as well as local settings) can be found in supplementary material 1 . A potential reason for this contradiction, in the face of measures to improve primary care, is that health outcomes are equally dependent on patient health-behaviours, which is in turn a function of patient knowledge of, and attitudes towards stroke.

The successful implementation of health policy is not only dependent on health system related factors, but also sociocultural knowledge, attitudes and practices towards health activities and health outcomes (Bogale et al., 2021). A recent meta-analysis (Hou et al., 2017) of quantitative measures of stroke found that the validated stroke knowledge test (SKT) and cerebrovascular attitudes and beliefs (CABS-R) scales lack transferability due to the marked sociocultural variation between societies. Further, the authors of the review conclude that health systems should employ qualitative measures of stroke-related health behaviours due to the wide variation in sociocultural paradigms across contexts. For this purpose, numerous models such as the health belief model have come to the fore in efforts to disaggregate and explain social factors that influence health promotion and prevention activities (Rimer \& Glanz, 2005). The health belief model is an explanatory theory that lays the 
foundation for programme planning and development for evidence-based interventions and its utility in the study of stroke-related health behaviours has been well-established, both internationally and locally. It constitutes the concepts of Perceived Severity, Perceived Susceptibility, Perceived Benefits, Perceived Barriers, Cues to action and Self-Efficacy.

Seven international studies directly analyse stroke disease according to the health belief model (supplementary material 2). These studies illustrated the utility of the health belief model in either interpreting, predicting, or intervening in health-behaviour towards stroke. However, all of these studies were conducted in developed nations with similar demographic descriptions - educated, elderly, and mostly wealthy. The findings of these studies, although validating the use of the health belief model in qualitatively interpreting stroke-related health behaviors, cannot be applied to the South African setting due to marked variation in the sociocultural factors that shape these health beliefs.

Several studies were found in the South African setting that provided qualitative interpretations of stroke and contributory non-communicable diseases. A meta-ethnographic literature review by Greenwood and Mackenzie (2012) showed complex changes in relationship structures and individual autonomy in the lives of individuals who had suffered a stroke. While this review did not address specific health beliefs or behaviours, it clearly depicted how stroke disease impacts every aspect of an individual's reality. Community based participatory action research targeting an impoverished urban setting in the Western Cape of South Africa (Bradley \& Puoane, 2007) found a gross lack of knowledge about NCD's (diabetes and hypertension) and the risks associated with them. The authors noted that economic constraints and culturally-mediated health beliefs detracted from positive health behaviour. An observational study (Legg \& Penn, 2013) of the cultural perceptions around aphasia as a presentation of stroke concluded that the studied community's interpretation of stroke's presenting symptoms were not biomedically interpreted, but rather consisted of ethereal constructs that were linked to cultural frameworks. Kagee, Le Roux and Dick(Treatment Adherence among Primary Care Patients in a Historically Disadvantaged Community in South Africa: A Qualitative Study - Ashraf Kagee, Marieanna Le Roux, Judy Dick, 2007, n.d.) used semi-structured interviews to explore the factors contributing to and preventing treatment adherence for non-communicable diseases amongst 23 rural South African patients. The authors used thematic analysis to show how the patient's perceptions around the origins of illness impacted their volition and willingness to seek healthcare in this rural population. Kagee and van der Merwe(Kagee \& van der Merwe, 2006) applied the theory of planned behaviour to primary health care attendance and noted that the theory was able to account for $47 \%$ of the variance in intentions to adhere, and $23 \%$ of the variance in behavioural adherence. Bham \& Ross (2005) used semi-structured interviews to identify the health beliefs of both caregivers and traditional healers on the eastern coast of South Africa. The pretext assumed by the study was that cultural communities assigned different values to illness and health. Traditional healers provided the belief that stroke was an outcome of dysequilibrium between hot and cold within the body and the depletion of energy. Further, traditional healers believed that no one cause applied to all stroke victims presenting to them for care. Traditional healers used warm blood from pigeons to counteract the effect of the excess 'cold' that was causing the stroke. Other therapies used by traditional healers included olive oil, honey, rose, water that had been prayed over and replenishing depleted energy. Both caregivers and traditional healers were not aware of 
Western diagnostic and therapeutic strategies for stroke. Western therapies such as speech and language therapy were perceived as culturally inappropriate.Hundt et al. (2004) conducted a mixed method rapid ethnographic assessment in combination with household interviews of immigrant Mozambicans to ascertain the health beliefs and practices in this population group. The study found that the majority of individuals did not consider stroke as a primary health problem. Of the 35 participants, six used conventional western healthcare, three used only traditional healers, while 22 used a combination of both. Another standout feature of the study was the significant economic and social burden incurred due to the frequenting of various healers.

An extensive search of Academic Search Premier and PubMed found no studies that explored the health beliefs of individuals who had suffered a stroke in South Africa as a determinant of health-behaviour. This paper aimed to develop qualitative insight into the determinants of health-behaviour through the lens of the Health Belief Model in an urban Gauteng setting.

\section{Methods}

We sought to provide a detailed exploration of contextual health beliefs around stroke disease and its risk factors to identify actionable patient-related determinants of health outcomes in this vulnerable patient group. We used semi-structured interviews (see appendix I for template) to obtain an intimate examination of the individual's unique perceptions of stroke disease. This period was conducted between December 2017 and April 2018.

Furthermore, semi-structured interviews were chosen as they can elicit specific answers from individuals (in this case, the tenets of the Health Belief model), while not limiting the individual, thematic emergence. The questions were: Have you had a stroke before? In your own words, how would you define a stroke? After that, questions were framed on the concepts of the Health Belief model:

- Perceived Severity: What was it like for you? How has your life changed since having a stroke? Perceived Susceptibility: Who do you think gets a stroke? What do you think causes stroke? What do you think your community thinks about stroke? What treatments are available for stroke? Do you think that you could suffer a stroke again?

- Perceived Benefits: Where can you receive care for stroke?

- Perceived Barriers: Do you do anything to reduce your risk of stroke? How do you receive care for stroke? What prevents you from receiving care for stroke?

- Cues to action and Self-Efficacy: If the participant provides interesting views or beliefs, ask probing questions to explore the concept/topic.

- Do you have anything else that you would like to add? Do you have any questions?

Framework analysis was used to evaluate the data through the lens of the Health Belief model. Emergent themes throughout the data were coded and categorised according to these central themes using MaxQDA (MAXQDA, n.d.).

\subsection{Sampling}


Convenience sampling was used to recruit participants rich in the data required to answer our research questions around local health beliefs. The population was patients, older than 18 years of age, who had suffered one or more strokes and attended the Tambo Memorial Hospital outpatient department for care of chronic diseases. The sample included individuals matching the inclusion criteria: individuals from the target and source populations mentioned above, who have sufficient capacity to consent to and engage in a semi-structured interview. Capacity to consent was ascertained using the Montreal Cognitive Assessment, a validated test to screen out cognitive impairment with a score of 27 or more - frequently used when assessing stroke victims (Nasreddine et al., 2005). No ethnic, gender, socioeconomic or religious criteria were applied to the sampling process. The concepts of idea and informational saturation informed sampling - fourteen one-hour interviews were conducted, although saturation was obtained after eleven interviews.

\subsection{Ethical Considerations and Risk Mitigation}

Semi-structured interviews risk a skewed power relationship in the intimate contact between the researcher and participant. The interviewer established rapport with participants to maintain open and honest interactions and ensure that the researcher did not intrude or impose on the autonomy of the individual. The researcher used reflexive appraisal of the participant's views to represent the participant's viewpoints appropriately. The researcher was not involved in the participants' care. Participants were fully informed of the research process by the researcher with the aid of the Participant Information Sheet (Appendix II). Further, due to potential unforeseen psychological complications of the interview, appropriate psychological and medical outpatient services were made available to participants post interview (Appendix III). We ensured that at least six months had passed since the most recent cerebrovascular event to reduce the risk of psychological trauma (Ethics in Qualitative Research: A View of the Participants' and Researchers' World from a Critical Standpoint - Dilmi Aluwihare-Samaranayake, 2012, n.d.). Approval was obtained from the University of Witwatersrand Human Research Ethics Committee (M171163) as well as the National Health Research Database (GP_201712_035).

\section{Results}

A total of 14 participants were sampled. Results are discussed according to participant profiles (tables $1 \& 2$ ) and then according to the tenets of the health belief model.

Table 1: Description of study population

\begin{tabular}{|l|l|l|l|l|l|l|l|}
$\begin{array}{l}\text { Interv } \\
\text { iew }\end{array}$ & Age & Ethnicity & Gender & Marital Status & $\begin{array}{l}\text { Household } \\
\text { Income }\end{array}$ & $\begin{array}{l}\text { Level of } \\
\text { Education }\end{array}$ & \begin{tabular}{l} 
Status \\
\hline 1
\end{tabular} \\
\hline 2 & 62 & African & Male & Divorced & $<10000$ & Primary School & Unemployed \\
\hline 3 & 44 & Coloured & Female & Married & $10000-20000$ & Primary School & Pensioner \\
\hline 4 & 53 & Female & Divorced & $>20000$ & $\begin{array}{l}\text { Postgraduate } \\
\text { Studies }\end{array}$ & Employed \\
\hline 5 & 47 & African & Female & Divorced & $10000-20000$ & High School & Employed \\
\hline
\end{tabular}




\begin{tabular}{|l|l|l|l|l|l|l|l|}
\hline 6 & 57 & White & Male & Life Partner & $<10000$ & $\begin{array}{l}\text { Postgraduate } \\
\text { Studies }\end{array}$ & Unemployed \\
\hline 7 & 58 & African & Male & Divorced & $>20000$ & High School & Employed \\
\hline 8 & 69 & African & Female & Divorced & $10000-20000$ & High School & Pensioner \\
\hline 9 & 57 & Coloured & Female & Married & $10000-20000$ & High School & Self-Employed \\
\hline 10 & 67 & African & Female & Widow & $<10000$ & Primary School & Pensioner \\
\hline 11 & 52 & African & Male & Divorced & $10000-20000$ & High School & Employed \\
\hline 12 & 24 & African & Female & Single & $>20000$ & High School & Unemployed \\
\hline 13 & 58 & White & Female & Life Partner & $10000-20000$ & $\begin{array}{l}\text { Postgraduate } \\
\text { Studies }\end{array}$ & Unemployed \\
\hline 14 & 50 & African & Female & Divorced & $10000-20000$ & High School & Self-Employed \\
\hline
\end{tabular}

All of the participants resided in the drainage area of Tambo Memorial Hospital. The average household income was significantly lower than the national average of R 165000 per household (Statistics South Africa, 2015) highlighting the relative poverty in which the sample population find themselves. Five participants had continued to work following the onset of stroke disease, two had started small entrepreneurial shops, five had lost employment or been unable to work following the onset of stroke, and two were retired pensioners.

Table 2: Risk Factors

\begin{tabular}{|l|l|l|}
\hline Interview & Modifiable Risk Factors & Date of Stroke \\
\hline 1 & HIV, Hypertension, Alcohol, Smoking & September 2010 \\
\hline 2 & Hypertension, Smoking & April 2012 \\
\hline 3 & Hypertension, Smoking & December 2012 \\
\hline 4 & Hypertension, Smoking & October 2016 \\
\hline 5 & Hypertension, HIV & January 2015 \\
\hline 6 & Hypertension, Alcohol & March 2016 \\
\hline 7 & Hypertension, Diabetes & August 2017 \\
\hline 8 & Hypertension & June 2016 \\
\hline 9 & Hypertension, Diabetes & July 2015 \\
\hline 10 & Hypertension, Diabetes & April 2017 \\
\hline 11 & Hypertension, Smoking, Alcohol & April 2017 \\
\hline 12 & HIV (Vertical Transmission) & May 2016 \\
\hline 13 & Hypertension, Smoker & November 2015 \\
\hline 14 & Hypertension & July 2017 \\
\hline
\end{tabular}

Table 2 shows the modifiable risk factors prevalent in the sample: hypertension $(\mathrm{n}=13)$, smoking $(\mathrm{n}=6)$, diabetes mellitus type II $(n=3)$, excessive alcohol $(n=3)$ and $\operatorname{HIV~}(n=3)$. The mean period since the occurrence of the stroke until the time of interview was 31 months, with a range between six and 89 months (see Table 10). All individuals had only suffered a single stroke. 


\subsection{Perceived susceptibility to stroke}

The overwhelming sentiment from participants was an absence of perceived susceptibility to stroke disease. Further, at the onset of stroke disease, participants were unable to interpret the symptoms and subsequently delayed medical intervention by periods of up to several months at times. Participants had a gross lack of knowledge about the origins and causes of stroke disease, often attributing it to negative past experiences or superstitious beliefs. There was an overall absence of insight into communicable and non-communicable diseases as risk factors for stroke.

"You never thought you can be like this" P7.

"The strokes started when the mother of my child passed on. The kids claimed that I was abusing them, then I was arrested for it... It was because of me being arrested." - PI

"Somebody, maybe they bewitched me, intentionally cursed me." - P5

"Some other guy, they told me, sometimes if you, you think too much, you gonna be stroke. Or it's stress, something like that." P11

There was a heightened awareness around stroke in participants following the initial event. However, some participants still considered themselves as insusceptible to a recurrent stroke,

"I don't believe in another stroke. I don't want another one. That's the truth, uh-uh." - P9

Only four participants acknowledged the risk of a recurrent stroke.

\subsection{Perceived Severity of Stroke}

Stroke was considered as a devastating disease by both patients and their families. Perceptions of severity were influenced by the participant and bystander experience at the time of disease onset. Participants also perceived the severity of stroke by considering its outcome. Participants considered stroke to be a disease worse than death. Poor social circumstances (poverty and unemployment, social isolation and lack of transport) compounded the perceived severity of stroke disease. Stroke survivors noted immense feelings of anxiety, fear and depression around their disability that heightened the perceived severity of stroke.

"This stroke is the worst I ever in my life have seen" - P7 
"Yoh. Death. I'm telling you. Death. If you not going to be disabled for the rest of your life, you either disabled or dead." - P10

"They judging me, others insult me, told me that I am now a cripple... and you are cursed, something like that" - P5

\subsection{Perceptions of self-efficacy}

Pre-existing social isolation, or that after the stroke event, detracted from the participants' sense of self-efficacy. One participant aptly described the predominant lack of social support.

"I don't have too much family. Um, is my father, my mother, my grandmother, passed away. I got no sister, I got no brother, I'm alone at home." - P7

Further, while the absence of social support contributed to lack of self-efficacy, participants experienced personal disdain about being dependent on other people.

“I can't do things like I used to do, when I was alright, like cleaning cupboards, then I can't get on my knees, I need to ask my son to help, I can't climb onto a chair, there are other things that I can't do. And when I have fallen, then I can't get up again. Unless there is something that I can hold on to. But, on my own, I can't get up. Someone must help me." - P4

“...but if I'm taking the long way, I'm using the stick. But I can't use, do nothing with the hand. I can't cook now, by myself. And I can't wash me, only my wife that help me to the washing”- P11

Lastly, stroke survivors perceived themselves as vulnerable members of society, falling victim to crime, abuse, poverty and forced unemployment with minimal capacity to change their circumstances.

\section{$\underline{3.4 \text { Perceptions of benefits }}$}

Participants' perceptions of benefits around receiving treatment were shaped by personal and community beliefs, the experience of health services, recovery in functionality, and potential access to therapeutic strategies. Personal and community beliefs were shaped by the lived experiences of others as well as the individual and family hope of recovery. As participants utilised therapeutic strategies, their perceptions of benefits would grow - whether from measurable improvements in functionality or from the cognitive construct of active engagement in improving one's health. Medications were viewed as beneficial although participants could express reasons for this, other than it was prescribed by a health care provider. Participants also practiced alternative treatment strategies for potential perceived benefits. 
"I will immediately feel when I didn't take my aspirins for a few weeks. I can feel like my heart is beating heavy" - P3

"But the hand that is ok is working even more to support the other one that is not working when I drink the medication" - P1

"My life comes first. I've got to do what I have to do" - P7.

"But, you have to force your things, you have to force yourself on when you have got a stroke.

Especially take the medicine." - P14

"My father was just come in, pray for me and rub me with the vinegar and the, the sour lemon. I never went to a Doctor or anything" (P9)

The hope for recovery from stroke was a strong behavioural driver for adherence to all treatment strategies. Elation experienced on attaining progress in physical activities prescribed by a physiotherapist provided overwhelming incentive to continue treatment.

"I just call my husband and said come here, I want to show you something" - P9

Nearly all participants expressed expectations of benefits not directly related to treatment strategies for stroke. These included health education, a means to be integrated into the healthcare system, re-integration into society, lifestyle counselling and social assistance.

"The thing that makes me come to you is because I cannot any longer sign with the hand, because it is affected on the right hand, using the right hand, so, now I have to use the thumb to sign. When I want to get an ID (identity document) at the police station, they told me to come to the doctor first." - P1

\subsection{Perceptions of Barriers to Treatment}

Participant-led discussions during the SSI's trended towards their perceptions of barriers to treatment. Effective attendance at the outpatient facility was marred by system errors such as poor service, long waiting times, a lack of follow-up, and asynchronous care within and between private and public sectors. Participants found dietary changes challenging due to the cost of healthy food choices, unawareness of healthy food options, and multiple household dependents. The absence of a safe environment, social stigmatisation and physical inability to perform activities served as barriers to physical exercise. Financial constraints were found to be a barrier for all participants in accessing and receiving treatment. Participants perceived medical practitioners as arrogant, indifferent and reductionistic. Further, health care providers were viewed as paternalistic, failing to educate and collaborate with their patients. 
"When I came to hospital, they give me another date to come back and take $x$-rays because the machine was broken, so the following day, when I must come to take $x$-rays, the machines were, they said the machines were not working." - P7

"I remember one night I woke up because I heard this yelling "Help, help, help" all the time, and I woke up and I went to the room to see where the night nurses is, and they were all in the front in the reception area, the doors were locked, and I peeped through the window, and they were all asleep." P3

"She turns my face like this and she puts the medication in my mouth and takes water in a bottle and she forces me to swallow it." - P13

"The problem is the money and the food. After receiving the medication from the clinic I have to take food before I drink the medication, so I don't have food." - P1,

"But, you know what, they [neighbours] talk to me now, don't drink that tablets, because if you drink that tablet, you never woke up again" - P9

Doctors were seen mostly as antagonists to participants receiving appropriate treatment. Doctors were perceived as indifferent.

"I went back to my GP after I came out of hospital. But it didn't seem like he was very interested in me." - P13

Participants reported that doctors dehumanised them and failed to provide the necessary health education around stroke.

"Ja, I'm not mentally retarded or anything." - P6

\subsection{Cues to Action}

Participants cited a lack of knowledge around stroke, its causes, symptoms and treatment options, and how this inhibited their seeking treatment. They felt that this resulted in them not being aware of any 'cues to action'. Some participants were unable to recognise the symptoms of stroke. One participant had been uncertain of the symptoms and had hoped that they would pass in a few days. Universally, participants described no motivation to protect their health and prevent a stroke prior to the initial episode. Only when participants had suffered a stroke did their symptoms drive them to seek help, although frequently delayed and mis-ascribed.

"It's like being shocked by electricity" - P1 
"So, we kept on and then, later on, they said after three months, they said it is a stroke" - P12

"So, I called my Pastor, I said I got a very bad feeling, he must come and pray with me, because I don't know what feeling is this now" - P9

Only three participants were aware of and acknowledged their risk of stroke recurrence. These participants viewed physical activity, medication adherence and dietary and behavioural changes as beneficial methods of reducing their respective risk for stroke.

\section{Discussion}

The overarching aim of this study was to qualitatively interpret the health beliefs around stroke in an urban South African setting. We identified in the literature review that stroke disease, a burgeoning public-health problem for developing nations, is a poorly researched entity outside of a positivist paradigm. Further, we argued that a disconnect between the current trajectory to bolster PHC services and the increasing burden of stroke disease could be accounted for by aberrant health-behaviours amongst individuals and communities around stroke. Through enhancing the currently limited qualitative understanding of stroke disease in South Africa, we believed that our study would provide valuable insight to guide targeted public-health interventions. This approach was abased in the belief that most strokes are preventable due to the long subclinical phase of stroke disease, and that a host of modifiable risk factors amenable to behavioural change were prevalent. The Health Belief Model, an extensively validated and utilised model for the analysis of health behaviour, formed the a priori themes used in the framework analysis of the 14 interview transcripts.

The findings of this study echo those of studies in alternate settings (Kamal et al., 2015) that stroke knowledge correlates with the tenets of the HBM, and subsequently stroke-related health behaviour. However, where these works showed that increasing knowledge around stroke positively influenced health behaviour, our study showed that an absence of stroke knowledge has a markedly detrimental effect on the population's healthbehaviours. Similar to the study by Samsa et al. (Samsa et al., 1997) this study found that stroke awareness, in the absence of health promotion campaigns, increased only once individuals had suffered from a stroke. The study by Legg and Penn(Legg \& Penn, 2013) conducted in a rural South African setting, found that community interpretation of aphasia had strong sociocultural underpinnings. While our study found the same, the categories of sociocultural perceptions were markedly different, likely due to ethnographic and contextual variation. Further, this finding highlights that the paradigm through which the stroke patient views the natural history (as well as the therapy) of stroke disease is strongly influenced by their sociocultural and religious frames of reference.

The deficiency of health information and awareness services by the current healthcare system is underscored by the fact that the majority of participants did not know the causes, symptoms, outcome or management options of stroke. Further, there is an absence of discourse around stroke between individuals, communities and state. 
Drawing from the theory of the Health Belief Model (Green \& Murphy, 2014), where the perceived threat (as a modifying factor) is a product of the perceived susceptibility and severity of a disease, it is evident why the population is indolent toward behavioural changes reducing the risk for stroke, as perceived susceptibility is near absent, even after incurring a stroke.

The severity of stroke was perceived in relation to the individual's outcome, their interpretation of symptoms and the disruption of daily life that they experienced. Further, participants noted that practitioners regarded disease severity as a purely biomedical occurrence that disrupted the individual's functionality (grading severity according to a clinical grading tool and subsequently developing linear, incomplete, management plans), whereas participants in our study perceived the severity of stroke within the greater context of themselves. The needs that they had were not met by the reductionistic structure of the healthcare system. The dilemma is that perceptions of severity were not tangible until the participants in our study had been directly affected by stroke, which influenced perceived threat as a modifying factor of behavioural change too late. Greenwood and Mackenzie (2014) found that the occurrence of a stroke carries a significant burden for both the patient's families and caregivers. This finding was not directly researched in this study, although most participants reported a lack of the presence and support of a family and near absence of a personal caregiver. The difference between the findings of these studies highlights the disproportionate burden of stroke suffered by participants in urban settings due to the phenomenon of the family breakdown associated with urbanisation (Bradshaw et al., 2019).

An uncertainty around potential benefits of receiving treatment was evident. All participants were not aware of holistic and complete treatment strategies available to them. As participants used healthcare services, they intuitively began to perceive a more significant benefit from treatment strategies. There was a prevailing social norm of trust in the western model of healthcare services, often founded in nothing other than submission to a paternalistic healthcare system. Surprisingly, participants perceived benefits of receiving treatment for stroke outside of conventional treatment strategies. These benefits included receiving linkages to socioeconomic relief, letters validating disability for home affairs and welfare services, and medical education. The perceptions of extra-medical benefits highlight the macroeconomic needs of the stroke patient in the urban South African setting. Perceptions of benefits were found to be a less-than-necessary driver for behavioural change.

Myriad barriers flooded the perceptions of the research participants. Nearly every element in the chain of receiving stroke care (from finance and transport to medical facilities and treatment strategies) provided potential barriers. Adverse socioeconomic circumstances set the foundation for perceptions of barriers to receiving care in participants. Current health care systems were perceived as a frustration, lacking integration and coordination. Overall, challenges experienced in receiving treatment and performing positive behavioural changes heightened participants perceptions of barriers to receiving treatment, further resulting in participants feeling disabled to perform healthy stroke behaviour. Perceptions of barriers overwhelmed perceptions of benefits resulting in a figuratively 'negative' likelihood of action (the difference between perceptions of benefits and barriers). 
This is a striking indictment on all levels of stroke patient care in urban South Africa. Contrary to the study by Sullivan et al. (Sullivan et al., 2009) that found that perceptions of susceptibility (above other tenets of the Health Belief Model) were most useful in predicting stroke behaviour, this study's findings leaned strongly towards perceptions of barriers as the major predictor in determining health behaviour. Sullivan's (Sullivan et al., 2009) study was conducted in a developed nation with higher income per capita, improved socio-economic circumstances and better healthcare infrastructure than South Africa. This difference emphasises the need for local research that highlights the varying health needs of populations requiring tailored public health interventions. Hundt et al. (Hundt et al., 2004) found that most participants in their research had turned to traditional healers rather than conventional healthcare facilities due to a lack of perceived benefits from attending these facilities. While this study also found low levels of use of healthcare facilities due to a lack of perceived benefits, it did not find a similar dependence on traditional healers, possibly explained by the phenomenon of urbanisation and secularisation.

\section{Limitations}

It is argued that the Health Belief Model provides more of a descriptive than an explanatory model (Armitage \& Conner, 2000). Further, our study did not yield exhaustive insights into "cues to action" and "perceived selfefficacy", progressive elements of the extended Health belief model (Baum et al., 1997) that contribute to explaining health-related behaviour. It can be assumed that race and class bias was present in our study due to the inherent variations in the receptivity of participants based on their ethnography (Cannon et al., 1988). The use of the a priori themes of the health belief model to design the research methodology for framework analysis meant restricting the approach to the data to this model. Themes not related to the health belief model, whether health or non-health related, were inherently omitted from analysis and interpretation.

\section{Conclusion}

The findings of our study highlight that the current focus on the quantitative improvement of the healthcare systems in the urban South African setting is insufficient to address the extant burden of stroke disease by itself. As the country moves towards implementing UHC, policy makers must embed patient engagement and bottomup initiatives to drive commensurate societal ownership of their health and utilisation of healthcare services. There is an urgent need for public health campaigns raising public awareness about causes, risk factors, susceptibility and treatment options for stroke. Current healthcare structures must be audited to enhance the effectiveness and efficiency of the resources, reduce redundancy within the system, and enhance patient and practitioner experience. Lastly, long-term partnerships with other governmental departments must develop policies targeting macroeconomic upstream determinants of health and pushing for equality of health care for all citizens, regardless of socio-economic and racial profile.

\section{Declarations}

None to declare 



\section{References}

Armitage, C. J., \& Conner, M. (2000). Social cognition models and health behaviour: A structured review. Psychology \& Health, 15(2), 173-189. https://doi.org/10.1080/08870440008400299

Baum, A., Newman, S., Weinman, J., West, R., \& McManus, C. (1997). Cambridge handbook of psychology, health and medicine. Cambridge University Press.

Bham, Z., \& Ross, E. (2005). Traditional and western medicine: Cultural beliefs and practices of South African Indian Muslims with regard to stroke. Ethnicity \& Disease, 15(4), 548-554.

Bogale, A. L., Teklehaymanot, T., Ali, J. H., \& Kassie, G. M. (2021). Knowledge, attitude and practice of cervical cancer screening among women infected with HIV in Africa: Systematic review and metaanalysis. PLOS ONE, 16(4), e0249960. https://doi.org/10.1371/journal.pone.0249960

Bradley, H. A., \& Puoane, T. (2007). Prevention of hypertension and diabetes in an urban setting in South Africa: Participatory action research with community health workers.

Bradshaw, D., Nannan, N. N., Wyk, V. P., Laubscher, R., Groenewald, P., \& Dorrington, R. E. (2019). Burden of disease in South Africa: Protracted transitions driven by social pathologies. South African Medical Journal, 109(11b), 69-76. https://doi.org/10.7196/SAMJ.2019.v109i11b.14273

Cannon, L. W., Higginbotham, E., \& Leung, M. L. (1988). Race and class bias in qualitative research on women. Gender \& Society, 2(4), 449-462.

Day, C., \& Zondi, T. (2019). Measuring National Health Insurance: Towards Universal Health Coverage in South Africa. South African Health Review, 2019(1), 55-68.

Ethics in Qualitative Research: A View of the Participants' and Researchers' World from a Critical Standpoint-Dilmi Aluwihare-Samaranayake, 2012. (n.d.). Retrieved March 11, 2019, from https://journals.sagepub.com/doi/abs/10.1177/160940691201100208

Feigin, V. L., \& Krishnamurthi, R. (2011). Stroke Prevention in the Developing World. Stroke, 42(12), 36553658. https://doi.org/10.1161/STROKEAHA.110.596858

Feris, S. G., \& Naicker, B. (2020). Acute stroke in the emergency department: A chart review at KwaZulu-Natal hospital. South African Family Practice, 62(1), 4.

Goldstein, L. B., Adams, R., Alberts, M. J., Appel, L. J., Brass, L. M., Bushnell, C. D., Culebras, A., Degraba, T. J., Gorelick, P. B., Guyton, J. R., Hart, R. G., Howard, G., Kelly-Hayes, M., Nixon, J. V. I., Sacco, R. L., American Heart Association/American Stroke Association Stroke Council, Atherosclerotic 
Peripheral Vascular Disease Interdisciplinary Working Group, Cardiovascular Nursing Council, Clinical Cardiology Council, ... American Academy of Neurology. (2006). Primary prevention of ischemic stroke: A guideline from the American Heart Association/American Stroke Association Stroke Council: cosponsored by the Atherosclerotic Peripheral Vascular Disease Interdisciplinary Working Group; Cardiovascular Nursing Council; Clinical Cardiology Council; Nutrition, Physical Activity, and Metabolism Council; and the Quality of Care and Outcomes Research Interdisciplinary Working Group: the American Academy of Neurology affirms the value of this guideline. Stroke, 37(6), 1583-1633. https://doi.org/10.1161/01.STR.0000223048.70103.F1

Green, E. C., \& Murphy, E. (2014). Health Belief Model. In The Wiley Blackwell Encyclopedia of Health, Illness, Behavior, and Society (pp. 766-769). American Cancer Society. https://doi.org/10.1002/9781118410868.wbehibs410

Greenwood, N., \& Mackenzie, A. (2010). Informal caring for stroke survivors: Meta-ethnographic review of qualitative literature. Maturitas, 66(3), 268-276. https://doi.org/10.1016/j.maturitas.2010.03.017

Hou, W.-H., Hoffmann, T., Huang, Y.-J., Wu, T.-Y., Chen, S.-S., \& Hsieh, C.-L. (2017). A Systematic Review of Tests Assessing Stroke Knowledge. The Journal of Cardiovascular Nursing, 32(3), 271-280. https://doi.org/10.1097/JCN.0000000000000345

Hundt, G. L., Stuttaford, M., \& Ngoma, B. (2004). The Social Diagnostics of Stroke-Like Symptoms: Healers, Doctors and Prophets in Agincourt, Limpopo Province, South Africa. Journal of Biosocial Science, 36(4), 433-443. https://doi.org/10.1017/S0021932004006662

Kagee, A., \& van der Merwe, M. (2006). Predicting Treatment Adherence among Patients Attending Primary Health Care Clinics: The Utility of the Theory of Planned Behaviour. South African Journal of Psychology, 36(4), 699-714. https://doi.org/10.1177/008124630603600404

Kamal, A. K., Shaikh, Q., Pasha, O., Azam, I., Islam, M., Memon, A. A., Rehman, H., Akram, M. A., Affan, M., Nazir, S., Aziz, S., Jan, M., Andani, A., Muqeet, A., Ahmed, B., \& Khoja, S. (2015). A randomized controlled behavioral intervention trial to improve medication adherence in adult stroke patients with prescription tailored Short Messaging Service (SMS)-SMS4Stroke study. BMC Neurology, 15, 212. https://doi.org/10.1186/s12883-015-0471-5

Legg, C., \& Penn, C. (2013). A stroke of misfortune: Cultural interpretations of aphasia in South Africa. Aphasiology, 27(2), 126-144. 
Lozano, R., Naghavi, M., Foreman, K., Lim, S., Shibuya, K., Aboyans, V., Abraham, J., Adair, T., Aggarwal, R., Ahn, S. Y., Alvarado, M., Anderson, H. R., Anderson, L. M., Andrews, K. G., Atkinson, C., Baddour, L. M., Barker-Collo, S., Bartels, D. H., Bell, M. L., ... Memish, Z. A. (2012). Global and regional mortality from 235 causes of death for 20 age groups in 1990 and 2010: A systematic analysis for the Global Burden of Disease Study 2010. Lancet (London, England), 380(9859), 2095-2128. https://doi.org/10.1016/S0140-6736(12)61728-0

Maredza, M., Bertram, M. Y., Gómez-Olivé, X. F., \& Tollman, S. M. (2016). Burden of stroke attributable to selected lifestyle risk factors in rural South Africa. BMC Public Health, 16(1), 143. https://doi.org/10.1186/s12889-016-2805-7

MAXQDA: Qualitative Data Analysis Software|Windows \& Mac. (n.d.). MAXQDA - The Art of Data Analysis. Retrieved August 25, 2019, from https://www.maxqda.com/

Mayosi, B. M., \& Benatar, S. R. (2014). Health and health care in South Africa-20 years after Mandela. The New England Journal of Medicine, 371(14), 1344-1353. https://doi.org/10.1056/NEJMsr1405012

Nasreddine, Z. S., Phillips, N. A., Bédirian, V., Charbonneau, S., Whitehead, V., Collin, I., Cummings, J. L., \& Chertkow, H. (2005). The Montreal Cognitive Assessment, MoCA: A brief screening tool for mild cognitive impairment. Journal of the American Geriatrics Society, 53(4), 695-699. https://doi.org/10.1111/j.1532-5415.2005.53221.x

Rimer, B. K., \& Glanz, K. (2005). Theory at a glance: A guide for health promotion practice (2nd ed) [Electronic resource]. U.S. Dept. of Health and Human Services, National Institutes of Health, National Cancer Institute. http://www.cancer.gov/PDF/481f5d53-63df-41bc-bfaf-5aa48ee1da4d/TAAG3.pdf

Samsa, G. P., Cohen, S. J., Goldstein, L. B., Bonito, A. J., Duncan, P. W., Enarson, C., DeFriese, G. H., Horner, R. D., \& Matchar, D. B. (1997). Knowledge of risk among patients at increased risk for stroke. Stroke, 28(5), 916-921. https://doi.org/10.1161/01.str.28.5.916

Sullivan, K. A., White, K. M., Young, R. M., \& Scott, C. (2009). Predicting behaviour to reduce stroke risk in at-risk populations: The role of beliefs. International Journal of Therapy and Rehabilitation, 16(9), 488-496. https://doi.org/10.12968/ijtr.2009.16.9.43767

Treatment Adherence among Primary Care Patients in a Historically Disadvantaged Community in South Africa: A Qualitative Study_Ashraf Kagee, Marieanna Le Roux, Judy Dick, 2007. (n.d.). Retrieved September 12, 2021, from https://journals.sagepub.com/doi/10.1177/1359105307076232 


\section{$\underline{\text { Supplementary material } 1}$}

\begin{tabular}{|l|l|}
\hline \multicolumn{2}{|l|}{ Table 1: Non-Modifiable Risk Factors for Stroke } \\
\hline Risk & Impact \\
\hline Age & $\begin{array}{l}\text { The incidence of stroke doubles for every decade of } \\
\text { age after 55 years (Ovbiagele and Nguyen-Huyn, } \\
\text { 2011). }\end{array}$ \\
\hline Sex & $\begin{array}{l}\text { A large meta-analysis by Appelros et al. (2003) } \\
\text { revealed that males suffer a 33\% higher incidence } \\
\text { rate and 41\% greater prevalence rate of stroke across } \\
\text { all age groups. However, Appelros et al. (2003) } \\
\text { showed that females suffer a worse disease severity - } \\
\text { incurring a case fatality rate of 25\% in comparison to } \\
\text { their male counterparts at 20\%. }\end{array}$ \\
\hline Race & $\begin{array}{l}\text { Black ethnic groups face a two-to-four-fold elevated } \\
\text { relative risk of stroke (Lloyd-Sherlock, 2010) }\end{array}$ \\
\hline Heredity & $\begin{array}{l}\text { Ovbiagele and Nguyen-Huyn (2011) found a two- } \\
\text { fold increase in incidence in first-degree relatives of } \\
\text { stroke patients. }\end{array}$ \\
\hline
\end{tabular}

\begin{tabular}{|l|l|}
\hline Table 2: Modifiable Risk Factors for Stroke \\
\hline Risk & Impact \\
\hline Hypertension & $\begin{array}{l}\text { Attributable proportion of 38\% and a relative risk of } \\
2.1 \text { (Maredza et al., 2016). }\end{array}$ \\
\hline Obesity & $\begin{array}{l}\text { Attributable portion of 20\% and a risk ratio of 1.6 } \\
\text { (Maredza et al., 2016). }\end{array}$ \\
\hline Smoking & $\begin{array}{l}\text { Odds ratio of 1.91 (Ovbiagele and Nguyen-Huyn, } \\
\text { 2011). }\end{array}$ \\
\hline Dyslipidaemia & $\begin{array}{l}\text { Odds ratio of 1.6 (Ovbiagele and Nguyen-Huyn, } \\
\text { 2011). }\end{array}$ \\
\hline Diabetes & $\begin{array}{l}\text { Odds ratio of 1.3 (Ovbiagele and Nguyen-Huyn, } \\
\text { 2011). }\end{array}$ \\
\hline Alcohol Use & $\begin{array}{l}\text { Odds ratio of 4.11 associated with high intake of } \\
\text { alcohol, while moderate intake had an odds ratio 2.05 } \\
\text { (Ovbiagele and Nguyen-Huyn, 2011). }\end{array}$ \\
\hline Human Immunodeficiency Virus (HIV) & $\begin{array}{l}\text { Rasmussen et al. (2011) found an incidence adjusted } \\
\text { rate ratio of 1.60 in individuals with HIV, while } \\
\text { Chow et al. (2012) found a hazard ratio of 1.40 in } \\
\text { patients infected with HIV. Further, higher rates of } \\
\text { stroke are found in individuals with lower CD4 } \\
\text { counts (Chow et al., 2012) and higher viral loads } \\
\text { (Rasmussen et al., 2011) }\end{array}$ \\
\hline
\end{tabular}


Supplementary material 2: Summary of Qualitative Literature on Stroke and Non-Communicable Diseases in South Africa

\begin{tabular}{|c|c|c|c|}
\hline Authors & Aim & Method & Conclusion \\
\hline $\begin{array}{l}\text { Greenwood } \\
\text { and } \\
\text { Mackenzie, } \\
2010 .\end{array}$ & $\begin{array}{l}\text { To review } \\
\text { qualitative } \\
\text { literature on } \\
\text { informal stroke } \\
\text { caregiver's } \\
\text { experience. }\end{array}$ & $\begin{array}{l}\text { Application of meta- } \\
\text { ethnography to } \\
\text { literature review of } \\
\text { stroke car's } \\
\text { experience. Total of } \\
\text { seven studies used. }\end{array}$ & $\begin{array}{l}\text { The occurrence of a stroke has a significant } \\
\text { knock-on effect on the family and } \\
\text { community. Healthcare providers must be } \\
\text { made aware of caregiver struggles and } \\
\text { partner with families to improve patient as } \\
\text { well as their own quality of life. }\end{array}$ \\
\hline $\begin{array}{l}\text { Bradley and } \\
\text { Puoane, } 2007 .\end{array}$ & $\begin{array}{l}\text { To analyse } \\
\text { community } \\
\text { knowledge of } \\
\text { non- } \\
\text { communicable } \\
\text { diseases and } \\
\text { factors } \\
\text { influencing health } \\
\text { behavior. }\end{array}$ & $\begin{array}{l}\text { Community based } \\
\text { participatory action } \\
\text { research in an } \\
\text { impoverished setting } \\
\text { in the Western Cape } \\
\text { of South Africa. }\end{array}$ & $\begin{array}{l}\text { The authors found a gross lack of knowledge } \\
\text { about non-communicable diseases and their } \\
\text { risk factors. Adverse socioeconomic } \\
\text { circumstances contributed to poor dietary } \\
\text { choices and a lack of physical activity. }\end{array}$ \\
\hline $\begin{array}{l}\text { Legg and } \\
\text { Penn, } 2013 .\end{array}$ & $\begin{array}{l}\text { To explore } \\
\text { cultural } \\
\text { interpretation of } \\
\text { aphasia as } \\
\text { presenting } \\
\text { symptom of } \\
\text { stroke in a South } \\
\text { African township. }\end{array}$ & $\begin{array}{l}\text { Data for the study } \\
\text { was drawn from a } \\
\text { larger three-year } \\
\text { ethnographic } \\
\text { observational study } \\
\text { analyzing cultural } \\
\text { interpretation of } \\
\text { aphasia. }\end{array}$ & $\begin{array}{l}\text { The authors found that community } \\
\text { interpretation of aphasia had strong } \\
\text { sociocultural underpinnings. The authors } \\
\text { advocated that this provide theoretical and } \\
\text { clinical evidence for anthropology when } \\
\text { researching biomedical diseases. }\end{array}$ \\
\hline $\begin{array}{l}\text { Kagee, Le } \\
\text { Roux and } \\
\text { Dick, } 2007 .\end{array}$ & $\begin{array}{l}\text { To explore the } \\
\text { factors enabling } \\
\text { and disabling } \\
\text { treatment } \\
\text { adherence } \\
\text { amongst patients } \\
\text { with non- } \\
\text { communicable } \\
\text { diseases. }\end{array}$ & $\begin{array}{l}23 \text { semi-structured } \\
\text { interviews were used. } \\
\text { Thematic analysis } \\
\text { grounded in pure } \\
\text { inductive reasoning } \\
\text { (i.e. no framework } \\
\text { was used). }\end{array}$ & $\begin{array}{l}\text { The authors found central themes of patient's } \\
\text { perceptions around origins of the illness, how } \\
\text { they experienced disease, and what they } \\
\text { thought were the consequences of poor } \\
\text { adherence. The themes correlated with those } \\
\text { of the Health Belief Model. }\end{array}$ \\
\hline $\begin{array}{l}\text { Kagee and van } \\
\text { der Merwe, } \\
2006 .\end{array}$ & $\begin{array}{l}\text { To ascertain the } \\
\text { accuracy of the } \\
\text { Theory of } \\
\text { Planned } \\
\text { Behaviour (TPB) } \\
\text { in explaining and } \\
\text { predicting } \\
\text { intention and } \\
\text { behavior in } \\
\text { treatment } \\
\text { adherence. }\end{array}$ & $\begin{array}{l}\text { Questionnaires were } \\
\text { completed by } 117 \\
\text { previously } \\
\text { disadvantaged South } \\
\text { Africans living with } \\
\text { diabetes and } \\
\text { hypertension. }\end{array}$ & $\begin{array}{l}\text { The authors noted that TPB could account for } \\
47 \% \text { of the variance in intentions to adhere, } \\
\text { and } 23 \% \text { of the variance in behavioural } \\
\text { adherence. }\end{array}$ \\
\hline $\begin{array}{l}\text { Bham and } \\
\text { Ross, } 2005\end{array}$ & $\begin{array}{l}\text { To investigate the } \\
\text { health beliefs } \\
\text { around stroke in a } \\
\text { South African } \\
\text { Indian Muslim } \\
\text { community. }\end{array}$ & $\begin{array}{l}\text { Content Analysis of } \\
\text { semi-structured } \\
\text { interviews with ten } \\
\text { stroke patients and } \\
\text { ten traditional } \\
\text { healers. }\end{array}$ & $\begin{array}{l}\text { The authors found that both stroke patients } \\
\text { and traditional healers had strong beliefs in } \\
\text { superstitious causes and treatment methods of } \\
\text { stroke, with a lack of awareness of Western } \\
\text { diagnostic and therapeutic strategies. }\end{array}$ \\
\hline $\begin{array}{l}\text { Hundt et al., } \\
2004\end{array}$ & $\begin{array}{l}\text { To ascertain the } \\
\text { health beliefs and } \\
\text { practices of } \\
\text { immigrant } \\
\text { Mozambicans }\end{array}$ & $\begin{array}{l}\text { Mixed-method rapid } \\
\text { ethnographic } \\
\text { assessment in } \\
\text { combination with } \\
\text { household interviews }\end{array}$ & $\begin{array}{l}\text { Most participants turned to traditional healers } \\
\text { as a means to treat stroke rather than } \\
\text { conventional healthcare facilities. A } \\
\text { significant economic and social burden } \\
\text { incurred due to the frequenting of various } \\
\text { healers }\end{array}$ \\
\hline
\end{tabular}




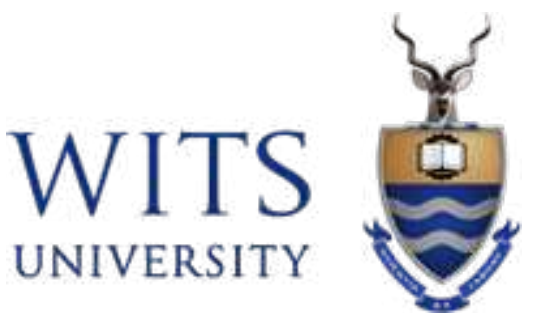

\section{For the Researcher:}

Name of Researcher: Shane Darren Murphy

Participant/Interview Number:

Participant Age:

Participant Gender:

Participant Ethnic Group:

Participant Religion:

Participant Level of Education:

Participant Marital Status:

Participant Residential Area:

Participants Risk Factors for Stroke:

Household Income:

\section{Guidelines for each Interview:}

- Greet participant and introduce yourself directly to the participant. Discuss your purpose (manage expectations), and establish rapport. Only the researcher and participant should be present, unless the participant requests the attendance of a family member or friend. Run through the consent form with the participant to ensure he/she understands all of the study's details.

- Maximum interview duration of 1 hour to avoid researcher/participant fatigue.

- Location: Private and confidential consulting room at tambo Memorial Hospital. Establish warm/friendly environment.

- Timing: During the day when participants have attended the Tambo Memorial Hospital outpatient facility.

- Jot down some important notes during the interview that interpret emotional or ethnographic milieu. Ensure that the audio-recorder is working/batteries are charged and operational.

- Use closed and open-ended questions.

- Pay full attention to the participant. Be respectful and culturally sensitive.

- It is critical to enable the interviewee to raise own issues. Ask questions tailored to local context.

- Remember that the template is not a questionnaire, but an agenda for the interview guide.

\section{Interview Questions:}

1. Have you had a stroke before?

2. In your own words, how would you define a stroke?

3. What was it like for you?

4. Who do you think gets a stroke?

5. What do you think causes stroke?

6. How has your life changed since having a stroke? 
7. What do you think your community thinks about stroke?

8. What treatments are available for stroke?

9. Do you think that you could suffer a stroke again?

10. Do you do anything to reduce your risk of stroke?

11. Where can you receive care for stroke?

12. How do you receive care for stroke?

13. What prevents you from receiving care for stroke?

14. If the participant provides interesting views or beliefs, ask probing questions to explore the concept/topic.

15. Do you have anything else that you would like to add?

16. Do you have any questions?

\section{Closure:}

Thank the participant for their time.

Provide the participant with a debriefing form. 


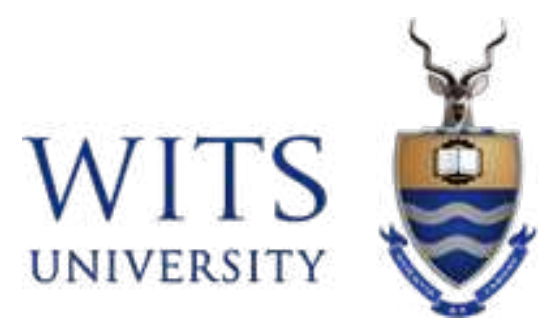

Research: Health beliefs around stroke in an urban South African setting: a qualitative study

Patients attending the Tambo Memorial Hospital Outpatient Department who have suffered stroke more than six months ago who are invited to participate in research, titled "An Interpretation of the Health Beliefs around Stroke in an Urban South African Setting”

Principle Investigator: Shane Darren Murphy

This Informed Consent Form has four parts:

- Information Sheet (to share information about the study with you)

- Participant Consent Form (for signatures if you choose to participate)

- Consent form to allow audio-recordings of interviews

- Relative's Consent to Stroke Patient's participation in MoCA Participant Information Sheet 


\section{Part I: Information Sheet Introduction}

\section{Introduction}

The researcher, Shane Darren Murphy, is completing research on stroke disease, a growing public health problem in South Africa. The researcher invites you to participate in a qualitative research project that explores the health beliefs around stroke in South African citizens who have suffered a stroke more than six months ago.

Please discuss any questions or concerns you have about the research with the researcher. If you do not understand some of the words or concepts within the sheet, please feel free to ask and the researcher will take the time to explain them to you at any stage of the research.

\section{Purpose of the research}

This research hopes to explore the South African citizens perceptions around stroke disease. Topics that will be discussed will cover items such as: how severe you believe stroke disease is, how vulnerable/susceptible you feel to stroke, and what do you regard as the benefits of seeking treatment, and possible barriers stopping you from getting appropriate treatment. This research is a first of its kind in South Africa, and by doing it we hope to understand what South African citizens believe about stroke, and how this can guide further health research and stroke disease care.

\section{Type of Research Intervention}

This research will involve your participation in a one-hour interview where we will discuss your perceptions of stroke.

\section{Participant Selection}

You, as an individual who has suffered from a stroke more than six months ago, are being invited to take part in this research because we feel that your experience as a stroke patient can contribute much to our understanding and knowledge of local beliefs about stroke.

\section{Voluntary Participation}

Please be assured that your participation in this research is entirely voluntary. It is your choice whether to participate or not. If you choose not to participate all the services that you receive at this centre will continue and nothing will change. 


\section{Montreal Cognitive Assessment}

A Montreal Cognitive Assessment test (MOCA) will be conducted on you to determine your ability (capacity) to both consent to, and engage in, an interview with the researcher. This test consists of a series of word and picture tests. A minimum score of 27 is required to pass. It will be necessary that both you, and a family member consent to you taking this test.

\section{Procedures}

We are asking you to help us learn more about the health beliefs of stroke in your community. We are inviting you to take part in this research. If you accept, you will be asked to participate in a 1 hour interview to discuss your health beliefs around stroke. You will enter a quiet and confidential consultation room. You will be able to ask any questions that you have about the research project. Then we will ask you questions about stroke and give you a chance to express your knowledge and beliefs. The questions will be about stroke disease, what you believe are the risks for developing stroke, what happens when you suffer stroke, how it is recognized, who people go to for help, and so forth. The interview will take place in a quiet and confidential consultation room. The interview will be audio-recorded so that the researcher can clearly remember what your responses are. No one else will be present during the interview, unless you request that someone else be there. You do not have to answer any questions that you are not comfortable with. None of your personal details will be shared, and no information will be linked to you. No one other than myself will have access to the recordings. All recordings will be permanently deleted once the master's studies are completed.

\section{Duration}

Your participation in this research will take only one hour of your time for the interview. No other commitments will be required of you.

\section{Risks/Warning}

We are asking you to share with us some very personal and confidential information, and you may feel uncomfortable talking about some of the topics. Further, due to the sensitive nature of stroke, you may experience undue psychological stress. You do not have to answer any question or take part in the interview if you don't wish to do so, and that is also fine. You do not have to give us any reason for not responding to any question, or for refusing to take part in the interview. Please see the 'Distress Protocol' section on who to contact if you feel that your participation in this interview has caused you undue psychological distress 


\section{Withdrawal Clause}

Please note that you, as the participant can choose to withdraw your consent to participate at any time for any reason deemed fit by you.

\section{Benefits}

There will be no direct benefit to you, but your participation is likely to help us find out more about how to prevent and treat stroke in your community.

\section{Reimbursements}

You will not be provided any incentive to take part in the research. However, we will ensure that you do receive the appropriate care that you have attended the facility for today.

\section{Confidentiality}

The research being done in the outpatient department may draw attention and if you participate you may be asked questions by other people in the department. We will not be sharing information about you to anyone outside of the research team. The information that we collect from this research project will be kept private. Any information about you will have a number on it instead of your name. Only the researchers will know what your number is and we will lock that information up with a lock and key. It will not be shared with or given to anyone.

\section{Sharing the Results}

Nothing that you tell us today will be shared with anybody outside the research team, and nothing will be attributed to you by name. The knowledge that we get from this research will be shared with you and your community before it is made widely available to the public. Each participant will receive a summary of the results. Following this, we will publish the results so that other interested people may learn from the research.

\section{Right to Refuse or Withdraw}

You do not have to take part in this research if you do not wish to do so, and choosing to participate will not affect the medical care you receive in any way. You may stop participating in the interview at any time that you wish without your care being affected. I will give you an opportunity at the end of the interview to review your remarks, and you can ask to modify or remove portions of those, if you do not agree with the researchers notes or if the researcher did not understand you correctly.

\section{Distress Protocol}

If you feel that this taking part in this interview has caused you any distress or psychological harm, please contact our counselling psychologist on: 0761634372, or email her at: 
lerato.psychologist@gmail.com. Alternatively you can visit her at: 130 Leeuwpoort St, Boksburg, Johannesburg 1470.

\section{Who to Contact}

If you have a concern, question or complaint about any aspect of your participation or any other queries please raise this with the investigator (details provided above). However, if you would like to contact an independent party please feel free to contact any of the below.

\section{Wits Human Research Ethics Council}

Prof C Penny, Tel 011717 2301, email Clement.Penny@wits.ac.zaisẸpiMs Z Ndlovu and Mr Rhulani Mkansi Administrative Officers 011717 1234/1252/2656/2700 zanele.ndlovu@wits.ac.za;

Rhulani.mkansi@wits.ac.za;

\section{For Psychological Distress Please Contact:}

Lerato Mokgheti, 0761634372; lerato.psychologist@gmail.com; 130 Leeuwpoort St, Boksburg, Johannesburg 1470. 


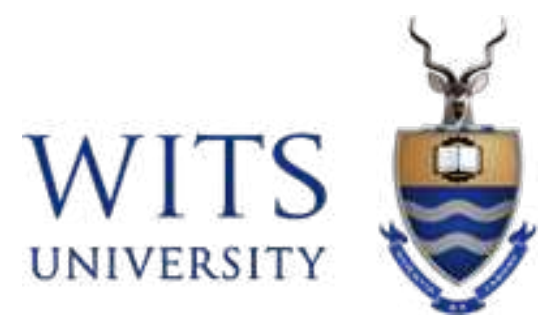

\section{PART II: PARTICIPANT CONSENT FORM}

Title of Research Project: Health beliefs around stroke in an urban South African setting: a qualitative study

\section{Investigator Contact Details:}

Name: Shane Darren Murphy

Department: University of Witwatersrand, Department of Family Medicine

University Address: Department of Family Medicine and Primary Care, Faculty of Health Sciences, University of the Witwatersrand, Parktown, Johannesburg, South Africa

Email: murphy.shanedarren@gmail.com

Telephone: +27748931153

\section{Consent Statement:}

I agree to take part in this research by engaging in a Montreal Cognitive assessment that assesses my capacity to engage in an interview, and enagaging in an interview of no longer than one hour. I am aware that I am free to withdraw at any point without giving a reason. I understand that the information I provide will be treated in confidence by the investigator and that my identity will be protected in the publication of any findings, and that data will be collected and processed in accordance with the Data Protection Act 1998 and with the University's Data Protection Policy.

Name

Signature

Date

Name of witness

Signature of witness

Date 
Please note: if you have a concern, question or complaint about any aspect of your participation or any other queries please raise this with the investigator (details provided above). However, if you would like to contact an independent party please feel free to contact any of the below.

\section{Wits Human Research Ethics Council}

Prof C Penny, Tel 011717 2301, email Clement.Penny@wits.ac.zașpips Z Ndlovu and Mr Rhulani Mkansi Administrative Officers 011717 1234/1252/2656/2700 zanele.ndlovu@wits.ac.za; Rhulani.mkansi@wits.ac.za;

\section{For Psychological Distress Please Contact:}

Lerato Mokgheti, 0761634372; lerato.psychologist@gmail.com; 130 Leeuwpoort St, Boksburg, Johannesburg 1470 . 


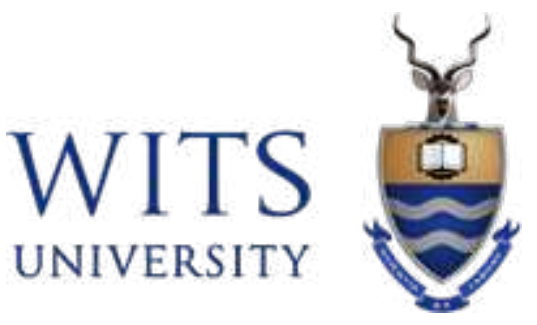

\section{PART III: AUDIO-RECORDING CONSENT FORM}

Title of Research Project: Health beliefs around stroke in an urban South African setting: a qualitative study

\section{Investigator Contact Details:}

Name: Shane Darren Murphy

Department: University of Witwatersrand, Department of Family Medicine

University Address: Department of Family Medicine and Primary Care, Faculty of Health Sciences, University of the Witwatersrand, Parktown, Johannesburg, South Africa

Email: murphy.shanedarren@gmail.com

Telephone: +27748931153

\section{Consent Statement:}

I agree to take part in this research, and am aware that I am free to withdraw at any point without giving a reason, although if I do so I understand that my data might still be used in a collated form. I consent to this interview being audio-recorded for later analysis by the researcher: Shane Darren Murphy

Name

Signature

Date

Name of witness

Signature of witness

Date

Please note: if you have a concern, question or complaint about any aspect of your participation or any other queries please raise this with the investigator (details provided above). However, if you would like to contact an independent party please feel free to contact any of the below. 


\section{Wits Human Research Ethics Council}

Prof C Penny, Tel 011717 2301, email Clement.Penny@wits.ac.zaišpins Z Ndlovu and Mr Rhulani Mkansi Administrative Officers 011717 1234/1252/2656/2700 zanele.ndlovu@wits.ac.za; Rhulani.mkansi@wits.ac.za;

\section{For Psychological Distress Please Contact:}

Lerato Mokgheti, 0761634372; lerato.psychologist@gmail.com; 130 Leeuwpoort St, Boksburg, Johannesburg 1470. 


\section{PART IV: Relative's Consent to Family Member's Participation in Montreal Cognitive Assessment}

Title of Research Project: Health beliefs around stroke in an urban South African setting: a qualitative study

\section{Investigator Contact Details:}

Name: Shane Darren Murphy

Department: University of Witwatersrand, Department of Family Medicine

University Address: Department of Family Medicine and Primary Care, Faculty of Health Sciences, University of the Witwatersrand, Parktown, Johannesburg, South Africa

Email: murphy.shanedarren@gmail.com

Telephone: +27748931153

\section{Montréal Cognitive Assessment Tool:}

This tool serves as a test to make sure that your family member has sufficient insight and capacity to both consent to and engage in an interview about the stroke that he/she has suffered.

\section{Consent Statement:}

$\mathrm{I}$, , spouse/parent/child/next of kin consent to my family member,

taking part in the Montréal cognitive assessment score being performed by the researcher, Shane Darren Murphy. I am aware that I am free to withdraw consent at any point without giving a reason.

Name

Signature

Date

Name of witness

Signature of witness

Date 
Please note: if you have a concern, question or complaint about any aspect of your participation or any other queries please raise this with the investigator (details provided above). However, if you would like to contact an independent party please feel free to contact any of the below.

\section{Wits Human Research Ethics Council}

Prof C Penny, Tel 011717 2301, email Clement.Penny@wits.ac.zaișẹpMs Z Ndlovu and Mr Rhulani Mkansi Administrative Officers 011717 1234/1252/2656/2700 zanele.ndlovu@wits.ac.za; Rhulani.mkansi@wits.ac.za;

For Psychological Distress Please Contact:

Lerato Mokgheti, 0761634372; lerato.psychologist@gmail.com; 130 Leeuwpoort St, Boksburg, Johannesburg 1470. 


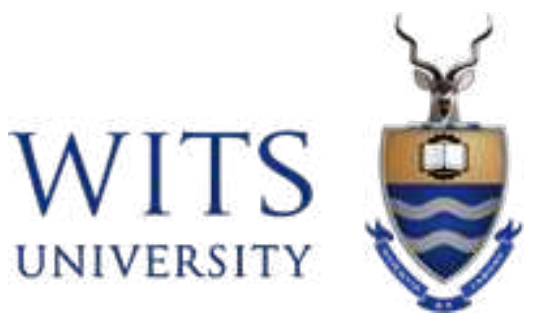

\section{RESEARCH PARTICIPANT DEBRIEF}

\section{Research Title: Health beliefs around stroke in an urban South African setting: a qualitative study}

Thank you very much for participating in the above study. Please detach and retain this part for your records. You may want to note your Personal Identification Number for future reference.

The aims of this study are to gain insight into the health beliefs around Stroke Disease in Urban South Africa

Your data are held securely and anonymously. If you wish to withdraw from the study, contact me with your personal identification code (see above) and your data will be removed from all files. You may withdraw from the study at any time, and your data will not be used for analysis or interpretation.

If you are a student, colleague, patient or in any other way have a dependent relationship with the researcher and you wish to withdraw from this study, you can be assured that this will not adversely affect the relationship in anyway.

Please note: if you have a concern, question or complaint about any aspect of your participation, please raise this with the researcher: Shane Murphy, murphy.shanedarren@gmail.com

Alternatively, please feel free to contact:

\section{Wits Human Research Ethics Council}

Prof C Penny, Tel 011717 2301, email Clement.Penny@wits.ac.za

Ms Z Ndlovu and Mr Rhulani Mkansi Administrative Officers 011717 1234/1252/2656/2700

zanele.ndlovu@,wits.ac.za; Rhulani.mkansi@,wits.ac.za;

If you feel that you need support for any psychological distress after participating in this study, please contact: Clinical Psychologist, Lerato Mokgheti, 130 Leeuwpoort St, Boksburg, Johannesburg, 1470.

076163 4372, lerato.psychologist@gmail.com 